\title{
Saúde e beleza do corpo feminino - algumas representações no Brasil do Século XX
}

\author{
Sandra dos Santos Andrade*
}

\begin{abstract}
Resumo: Há um conjunto de saberes e de instâncias a nos dizer o que é o corpo. Estas múltiplas instâncias como a mídia, a publicidade e a indústria, por exemplo, produzem diversas representações de corpo. Dentro do campo teórico dos Estudos Culturais e de Gênero, em que este texto se insere, representação é entendida como um modo de produzir significados no âmbito da cultura. Estes significados são produzidos através da linguagem e estão implicados em relações de poder. Através destas relações, posições de sujeito, diferenças e identidades são construídas. Neste texto busco situar o corpo, principalmente o feminino, como um construto histórico, social e cultural, produzido de múltiplas formas no tempo e no espaço. Localizo algumas das transformações, permanências e/ou rupturas operadas nas representações de corpo feminino na interrelação entre saúde e beleza no decorrer do século XX. Sinalizo, em alguma medida, como a medicina social higienista apropriou-se dos discursos eugênicos com o intuito de produzir novos conceitos de higiene, de saúde e de corpo em nome da população.Concluo que reconstruir e disciplinar o corpo para atingir a "boa forma", nos moldes como foi definido no decorrer do século XX, passa a ser um modo de viver a vida que deve ser incorporado ao cotidiano de cada um/a, bem como uma alternativa de prazer e saúde que conta com o uso dos mais diversos recursos tecnológicos e científicos. Palavras-chaves: corpo, saúde, beleza.
\end{abstract}

Muitas vezes nos perguntamos o que é o corpo: aquele cantado em versos ou aquele da ciência; aquele que a mão acaricia ou aquele da estética; aquele da juventude ou aquele da velhice; aquele da mídia e do mercado de consumo ou aquele descrito como natural; aquele do homem ou aquele da mulher; aquele da

\footnotetext{
* Prof ${ }^{\text {a }}$. substituta da FACED/UFRGS; prof ${ }^{\text {a }}$. da Faculdade de Pedagogia da Instituição Educacional São Judas Tadeu, membro do GEERGE (Grupo de Estudo Educação e Relações de Gênero).
}

Movimento, Porto Alegre, v. 9, n. 1, p. 119-143, janeiro/abril de 2003 
religião ou aquele da lei; aquele da arte ou aquele da medicina; aquele da cirurgia plástica ou aquele da academia. Como se vê, há diversas representações de corpo que passam pela medicina, pela biologia, pela poesia, pela cultura, pela arte, pela mídia, pelo econômico ou pelo social. Há alguns modelos de corpo vistos como padrão, hegemônicos; há também aqueles desviantes que insistem em fugir às regras. Enfim, o corpo é tudo aquilo que somos, mas também aquilo que nos escapa, que nos ultrapassa, que não nos pertence. A resposta a essa questão, "o que é o corpo?", indica alguns exemplos dos esforços de teóricos de várias áreas do conhecimento e das diferentes instituições para se apropriarem do corpo, principalmente do corpo feminino, ao longo dos tempos.

Admitindo este conjunto diverso de saberes, situo o corpo feminino como um constructo que é histórico, social e cultural, produzido de múltiplas formas em tempos e lugares diferentes. Foi a partir dos campos teóricos dos Estudos Culturais e Feministas, ancorados em uma perspectiva pós-estruturalista, que encontrei fundamentação para discutir o corpo feminino e os diferentes modos pelos quais ele aparece representado historicamente.

Aponto que este texto é um recorte de minha dissertação de mestrado. ${ }^{1}$ Nela analisei e discuti representações de corpo feminino produzidas e/ou veiculadas por um segmento da mídia - as revistas femininas - e, neste segmento, selecionei como corpus de análise a revista Boa Forma. ${ }^{2}$ Para realizar tal investigação, no entanto, foi necessário historicizar, minimamente, as transformações operadas nas representações de corpo feminino no Brasil produzidas na articulação entre saúde e beleza no decorrer do século XX; a fim de entender como foi (e ainda é) possível, ao longo da história e mediado pela cultura, a construção de determinadas representações acerca do corpo feminino, fixando outros e novos modos de ser mulher. Tais representações são entendidas, ao menos por um determinado tempo, como verdades, mas que deixam de sê-lo para dar lugar a outras representações.

Representação é um conceito importante para a escrita deste texto e é aqui entendido como um modo de produzir significados na cultura; esses significados são produzidos através da lingua-

1 A dissertação é intitulada "Uma boa forma de ser feliz": representações de corpo feminino na revista Boa Forma; orientada pela Professora Dra. Dagmar Estermann Meyer da linha de pesquisa Educação e Relações de Gênero do Programa de PósGraduação em Educação da UFRGS, defendida em 2002.

2 Indico, no entanto, que não utilizo neste texto nenhum elemento de análise da revista Boa Forma.

Movimento, Porto Alegre, v. 9, n. 1, p. 119-143, janeiro/abril de 2003 
gem e implicam relações de poder. É no interior dessas relações de poder que diferentes grupos sociais são significados e representados; é através dessas relações de poder que se estabelecem, também, no meio midiático, que o corpo feminino é significado e representado de um modo e não de outro ou, ainda, representado de múltiplas formas. Dagmar Meyer (2000), refere que

Representação envolve as práticas de significação e os sistemas simbólicos através dos quais estes significados - que nos permitem entendernossas experiências e aquilo que nós somos - são construídos. [...] A representação envolve, pois, as práticas de construção e partilhamento de sentidos na cultura, pela operação de diferentes e variados signos e sistemas de classificação (Meyer, 2000, p. 58).

Os sistemas de representação que operam com e através de redes de poder assumem o poder de nomear, descrever, classificar, identificar e diferenciar-o poder de definir, enfim, quem está incluído e quem está excluído de quais grupos/posições sociais (Meyer, 2000, p. 58), construindo, desta forma, posições de sujeito, diferenças e identidades. O que me importa aqui é perceber de que forma o corpo feminino está sendo representado na inter-relação entre beleza e saúde no século passado.

As representações de corpo ao longo do tempo, algumas vezes permanecem as mesmas, em outros momentos, sofrem rupturas e reformulações em relação aos padrões estéticos vigentes. Para localizar algumas dessas rupturas e/ou permanências, em um primeiro momento situo o corpo feminino como um construto histórico, social e cultural, produzido de múltiplas formas em cada época e lugar. Num segundo momento, localizo algumas transformações operadas nas representações de corpo feminino na inter-relação entre saúde e beleza no decorrer do século XX. Por fim, sinalizo como a medicina social higienista apropriou-se dos discursos eugênicos com o intuito de produzir novos conceitos de higiene, de saúde e de corpo em nome da população.

\section{O corpo como local de inscrição}

Nesses tempos (pós-modernos?), o corpo tem sido investigado, analisado, invadido, falado e ressignificado. Há uma infinidade de instâncias a nos dizer o que é o corpo. O olhar dessas diversas instâncias perscruta da pele às vísceras, do físico ao psíquico; fragmenta esse corpo em pequenas partes para entendê-lo nos seus mínimos e mais íntimos detalhes. A mídia, a publicidade, a indústria (cosmetológica, da moda, do fitness,...) tornaram o corpo um artefato do mercado econômico/social/cultural.

Movimento, Porto Alegre, v. 9, n. 1, p. 119-143, janeiro/abril de 2003 
Esse corpo do mercado de consumo é constantemente construído e reconstruído nessas discursividades, adquire uma materialidade que é, ao mesmo tempo, um produto do poder que gera divisões sociais. A inserção do corpo nessa rede de saberes que dizem sobre ele estabelece, sempre, novas relações de poder. O poder, entendido aqui na perspectiva foucaultiana, tem funcionado como um organizador de sistemas de classificação - sociais, culturais, políticas, econômicas -, interpelando, interagindo com cada um/a de modo a posicionar cada sujeito a ocupar seus devidos lugares nas representações que estão em jogo.

De modo geral, não só no senso comum, mas em uma gama de teorias das ciencias sociais e humanas, as relações de poder são vistas como negativas, como relações que distorcem, hierarquizam e deturpam as lutas pelos processos de significação, como se, por outra via, fosse possível atingir significados puros ou verdadeiros. Nas palavras de Tomaz Tadeu da Silva (1999, p. 23), os significados não são vistos como falsos ou verdadeiros, como puros ou contaminados, com o grau de falsidade ou de impureza sendo função do grupo que os produzem, que os enunciam.

O que interessa nessa abordagem teórica são os efeitos de verdade. Para dizer de outro modo, interessa delimitar/demarcar quais os aparatos que, produzidos em meio às relações de poder, governam as práticas de significação e são tomados como verdade. Isso se dá em um território marcado por múltiplas disputas e conflitos.

Nesse sentido, o corpo entendido como significante está necessariamente vinculado a relações de poder, as quais fixam e/ ou posicionam os sujeitos de modos específicos. Tais relações estão, de forma intrínseca, relacionadas com a produção de determinados saberes - sobre o corpo, sobre a sexualidade, sobre o que é ser homem ou mulher em determinado lugar ou tempo histórico. Ou seja, as relações de poder atuam (imbricadas numa rede de saberes) através ou sobre os corpos, em determinados contextos, produzindo efeitos de sentido, produzindo identidades sociais e culturais particulares. Outra passagem do texto de Silva pode elucidar essa colocação. O autor afirma que a identidade não é um produto acabado, ela é demarcada por meio de processos de produção da diferença.

A diferença e, portanto a identidade, não é um produto da natureza: ela é produzida no interior de práticas de significação, em que os significados são contestados, negociados, transformados (Silva, 1999, p. 25).

Movimento, Porto Alegre, v. 9, n. 1, p. 119-143, janeiro/abril de 2003 
O corpo, visto desde esta perspectiva, é um construto social e cultural alvo de diferentes e múltiplos marcadores identitários. É nele que marcas/símbolos culturais são inscritos e funcionam como um modo de classificar, agrupar, ordenar, qualificar, diferenciar, etc. Essas marcas posicionam de diferentes modos os sujeitos na escala social, determinando quem pertence ou não a certas classificações de corpo: magro, alto, belo, branco, jovem, heterossexual, saudável, entre outros. Esses marcadores identitários não são fixos ou estáveis, são objetos de uma contínua construção. Isso porque, como expressa Alfredo Veiga-Neto,

Vivemos numa época em que somos contínua e intensamente interpelados por marcadores identitários; vivemos numa época de proliferação das diferenças, em que os sentimentos de pertença são cambiantes e complexos, difíceis de capturar, descrever e analisar (Veiga-Neto, 2002, p. 35).

As representações de corpo feminino fazem parte desse processo de proliferação das diferenças e sofreram, ao longo do século XX no Brasil, muitas rupturas e transformações. Entretanto, houve/há muitas permanências e continuidades. As coisas que são ditas sobre ou vividas como corpo são produzidas em determinados períodos da história, são datadas e apresentam convergências e divergências; continuidades e descontinuidades; fraturas e permanências. Pode-se dizer, de modo geral, que as diferentes formas de representar o corpo ao longo da história foram produzidas, inventadas e atribuídas a esse ou aquele corpo também através de processos de identificação e significação. Enveredando pelas representações de corpo, Veiga-Neto diz

[... q que tudo isso é colocado em movimento não apenas para nos dizer quem somos - segundo um retículo de distribuições - e para que cada um se veja e se sinta dessa ou daquela maneira, mas também para que cada um aja disciplinadamente de acordo com o que se espera dos membros desse retículo (Veiga-Neto, 2002, p. 49).

Deste modo, não há, em nenhum período ou época, uma representação homogênea que serve para categorizar indistintamente a todos os corpos. O que se percebe é que as representações são inventadas, produzidas e que, por sua repetição, tornam-se hegemônicas e hierarquizam os sujeitos na escala social de acordo com diversos atravessamentos como gênero, classe, etnia, geração, etc. As representações circulam na esfera do social e legitimam o direito de capturar, nomear, enfim, de representar os sujeitos, pois somos prisioneiros das representações e do nosso próprio tempo já vivido e ainda por viver (Veiga-Neto, 2002, p. 55).

Movimento, Porto Alegre, v. 9, n. 1, p. 119-143, janeiro/abril de 2003 


\section{A beleza tratada como assunto de saúde}

O corpo está sempre sendo re/descoberto e re/inventado, e todas as marcas que se inscrevem ou se constróem em torno dele - nas artes, na medicina, na mídia, etc. - são sempre provisórias, características de cada época, cultura ou grupo social. Em função disso, pretendo mapear algumas das transformações colocadas ao corpo, principalmente o feminino, no decorrer do século XX no Brasil. Como referência, opero com as mudanças efetivadas pelos discursos que aliam beleza e saúde, localizando onde e como esse par se confunde, se diferencia e/ou se torna um mesmo e se ressignifica.

No decorrer do século XX, a imagem do que é saúde e do que é beleza sofre um deslocamento em relação a conceitos de períodos anteriores. A conquista de um corpo saudável e belo passa a ser entendida como um objetivo individual a ser atingido por meio de um exercício intencional de autocontrole, envolvendo força de vontade, restrição e vigilância constantes. Deborah Lupton (2000, p. 24) diz que a obesidade passa a ser vista como um sinal tangível de falta de controle, impulsividade, auto-indulgência, enquanto que o corpo magro é um testemunho do poder da autodisciplina, um exemplo do domínio da mente sobre o corpo e de um virtuoso sacrifício.

A busca por esse novo corpo belo e saudável durante o século XX acarretou, durante as últimas décadas, a substituição do açúcar nas gôndolas dos supermercados (e na mesa de uma significativa parcela da população que se sente interpelada pelo discurso da boa forma) por produtos light e diet.

Nestemomento aindústria de alimentos passa a oferecerinúmeras opções. Diferentemente do contexto pré-moderno, no qual a alimentaçãoémarcada pela tradição e rituais locais, na modernidade o alimento é desterritorializado, gerando uma oferta mundial de gêneros das mais variadas procedências (Mira, 2001, p. 191).

Esses produtos colaboraram para a configuração de outra conformação de corpo que se estabeleceu, um corpo mais magro e mais esguio. Com essa nova configuração, a relação do sujeito com o seu corpo é alterada: comer era/é um dos grandes prazeres que passa a ser cerceado em nome da boa forma. Entretanto, o bem-estar e o prazer colocam-se, ao mesmo tempo, cada vez mais como uma necessidade que deve estar presente em tudo e, nesse percurso, a mídia de modo geral colabora para confirmar essa necessidade. A esse respeito, Sant'Anna explicita que

Movimento, Porto Alegre, v. 9, n. 1, p. 119-143, janeiro/abril de 2003 
[... ] na medida em que o bem-estar se torna uma regra, nas cidades são multiplicados os serviços de prazer e conforto em tudo o que se faz: muitas publicidades de alimentos diet, por exemplo, defendem a aliança entre a dieta e o prazer de comer, termos incompatíveis no passado (Sant'anna, 2000c, p. 38).

Os alimentos diet e light também prometem um corpo mais saudável porque apresentam, em sua formulação, uma quantidade menor ou a ausência de gordura e açúcar, prevenindo contra o aumento excessivo nas taxas de colesterol, controle da diabetes e da obesidade. Na época em que vivemos, além de contar com esses novos produtos da indústria tecnológica de alimentos para reduzir a ingestão de calorias e facilitar a aproximação com esse corpo padrão, as pessoas têm à disposição academias com equipamentos ultramodernos que ajudam a queimar os excessos do corpo, onde homens e mulheres suam em torno de um mesmo desejo: a conquista de um abdômen enxuto e modelado.

Essa tática do mercado - de incentivo ao consumo de alimentos light e diet - reforça uma dada perspectiva de saúde que, através de práticas disciplinadoras e educativas, aponta normas de comportamento com a intenção de promover a saúde. Denise Gastaldo (1997, p. 148), ao discutir perspectivas de Educação em Saúde, afirma que esse é um processo educativo e, ao mesmo tempo, disciplinador, pois promove comportamentos que devem ser adotados pela população como um todo e interfere nas escolhas individuais, informando sobre como atingir estilos de vida "saudáveis". A autora refere ainda que o modelo de Medicina de Vigilância que passou a vigorar em meados do século XX muda o foco da medicina de corpos patológicos para cada um dos membros da população (Gastaldo, 1997, p. 151). Com isso, os limites entre saúde e doença, como escreve a autora, são reorganizados, e pessoas consideradas saudáveis podem ficar cada vez mais saudáveis, enquanto que outras podem ser saudáveis e doentes ao mesmo tempo. O cuidado com a saúde torna-se uma guerra permanente contra a doença, indica Zygmunt Bauman (2001, p. 93) em suas análises. A doença não é mais compreendida como um evento incomum, extraordinário, que pode ser tratado e que se apresenta com um começo e um fim. Ao contrário, é indicada como algo sempre presente, a sombra da saúde:

[...] seu outro lado é [uma] ameaça sempre presente: clama por vigilância incessante e precisa ser combatida e repelida dia e noite, sete dias por semana. [...]

E, finalmente o significado de um regime de vida saudável não fica parado. Os conceitos de dieta saudável mudam em menos tempo do que duram as dietas recomendadas simultânea ou sucessivamente (Bauman, 2001, p. 93).

Movimento, Porto Alegre, v. 9, n. 1, p. 119-143, janeiro/abril de 2003 
Nesse contexto, educar para viver de modo saudável significa investir constantemente em prevenção. Saúde é aí compreendida como uma responsabilidade individual que deve ser sempre atualizada. Algumas práticas mais radicais vão estimular o indivíduo a exercer poder sobre seu próprio corpo, sobre sua saúde. Esse controle sobre si mesmo para garantir a prevenção de doenças e, sobretudo, conquistar sempre mais saúde é alcançado, principalmente, através de informação sobre alimentação, exercícios físicos e sobre riscos provocados pelos hábitos de fumar e beber (Gastaldo, 1997, p. 152). O estímulo constante pela busca de saúde, de aptidão física e de prevenção de doenças incita um consumo crescente de novos produtos para emagrecer, queimar gorduras, desenvolver os músculos, de novas roupas esportivas, novos aparelhos de ginástica, novos espaços para a prática de exercícios. Acredito que essa busca incansável pela saúde e pela boa forma, que é marcada como uma competência do indivíduo, na mesma direção para a qual aponta Bauman, é como ir às compras:

Não se compra apenas comida, sapatos, automóveis ou itens de mobiliário. A busca ávida e sem fim por novos exemplos aperfeiçoados e por receitas de vida é também uma variedade do comprar, e uma variedade da máxima importância, seguramente, à luz das lições gêmeas de que nossa felicidade depende apenas de nossa competência pessoal mas que somos (como diz Michel Parenti) pessoalmenteincompetentes, ou não tão competentes como deveríamos, e poderíamos ser se nos esforçássemos mais (Bauman, 2001, p. 87).

A busca por saúde e boa forma física - ou aptidão, como denomina Bauman - organiza a vida em torno do consumo. Consumo não relacionado apenas com as necessidades básicas do sujeito, mas o consumo articulado ao desejo de ter, poder, adquirir, fazer. De acordo com o autor, o desejo

é uma entidade muito mais volátil e efêmera, evasiva e caprichosa, e essencialmentenão-referencial que as 'necessidades', um motivo autogerado e autopropelido que não precisa de outra justificativa ou causa (Bauman, 2001, p. 88).

Ou seja, o desejo tem a si mesmo como referência e não é, por isso, nunca saciado, nunca satisfeito, e acaba em uma via de mão dupla. De um lado, os produtores sempre preocupados em produzir novos desejos em seus consumidores a um elevado custo; de outro, consumidores insatisfeitos e prontos, rápidos, ágeis para irem às compras, alimentando, generosamente, a indústria capitalista.

Em séculos anteriores, a gordura foi sinônimo de saúde, beleza e sedução. No século XX, principalmente a partir da segunda metade, essa representação sofre modificações, talvez uma inversão. A magreza encarna o novo ideal de beleza, e a gordura

Movimento, Porto Alegre, v. 9, n. 1, p. 119-143, janeiro/abril de 2003 
é associada à doença, à falta de controle sobre o corpo e, por extensão, tambem falta de controle sobre a própria vida. O crescimento da indústria, as novas frentes de trabalho, a necessidade de mão-de-obra maior e melhor qualificada, a otimização do tempo e dos espaços exige corpos mais ágeis, mais aptos. Assim, o excesso de peso começa a atrapalhar, lembrando o ócio e a imobilidade e não combinando com a modernidade e os ares cosmopolitas do novo século. Isso mostra que as representações têm relação com as formas pelas quais o real e a realidade tornam-se efetivos para nós. O corpo é o local onde muitas lutas em busca de significados, inscritos em torno do social e do cultural, se concentram, se desdobram e se fazem re-apresentadas. Ele é produzido como um elemento discursivo de múltiplas instâncias econômicas, sociais e culturais, como, por exemplo, da mídia e da medicina. Produzido desse modo, o corpo incorpora e torna visíveis modos de ser e de viver no mundo, no qual alguns grupos têm o poder de representar e dizer pelo outro; esses grupos exprimem verdades que se legitimam e se tornam hegemônicas, produzindo, assim, sempre novos processos de significação que posicionam, de modos diferenciados, os sujeitos na ordem social.

As múltiplas identidades que constituem os corpos não são dadas ou naturais. As identidades só parecem fixas e sólidas quando vistas de relance, afirma Bauman (2001, p. 98). O que é ser gordo/ a ou magro/a, ser saudável ou doente, ser belo/a ou ser feio/a são representações que foram produzidas em determinados contextos históricos, de forma interessada e no interior de práticas de significação. Assim como o corpo e a identidade, os significados não são sempre os mesmos, não são fixos. Os significados são negociados, contestados, transformados, nunca completos ou acabados. Deste modo, a representação é aqui entendida como um processo de significação histórica socialmente localizado, pois o que hoje é entendido como sendo beleza e saúde é parte deste tempo, não era entendido desse mesmo modo no passado e, provavelmente, não será no futuro. Silva (1999, p. 32) acrescenta que conhecer e representar são processos inseparáveis e que a representação-compreendida aqui como inscrição, marca, traço, significante, e não como processo mental - é a face material, visível, palpável, do conhecimento. Nessa busca de significação e de novas representações harmonizadas com o século XX, a obesidade passa a ser indício de doença e de feiúra, e a magreza, análoga à saúde e à beleza.

Movimento, Porto Alegre, v. 9, n. 1, p. 119-143, janeiro/abril de 2003 
Muitas vezes, diz Sant'Anna (2001, p. 21), os espaços citadinos e seus equipamentos são os primeiros a excluir a presença dos seres pesados e grandes: em escolas, cinemas, teatros e aviões, as cadeiras costumam ser mais confortáveis aos magros e pequenos. Para sentirem-se incluídas nesses espaços citadinos, as pessoas buscam adaptar o seu corpo aos traços que constituem a norma. Com o objetivo de ser parte integrante de tais representações, o desejo e a obsessão pelo corpo magro, esbelto, leve e delicado assume centralidade nos dias atuais, tornando tais representações hegemônicas. No entanto, a essa representação, outras vão-se agregando ou dela se diferenciando. Como exemplo do que estou dizendo, desde os anos de 1990, aparecem os seios femininos em tamanhos significativamente maiores como destaque no corpo que continua esguio, tirando ou dividindo o espaço que era antes legítimo das nádegas e valendo qualquer sacrifício ou recurso científico para atingir esse fim, desde exercícios localizados para o peito, cremes e massagens até a prótese de silicone. Marilyn Yalom, no seu livro A História do Seio, refere que essa é uma preocupação também entre as americanas desde a década de 80 e que, estudos recentes

[...] de ciências sociais que procuram entender esse fenômeno sugerem que as mulheres estão infelizes com o seu corpo porque não se conformam com as figuras esguias e de seios grandes que pressentem que os homens preferem; de fato, as mulheres têm a tendência de sobrestimaro tamanho do seio quando avaliamo seu caráter geral de atração. Existem bons motivos para acreditar que a sociedade paga um preço muito acima do valor monetário ao alimentar a fantasia de corpos e seios perfeitos sem reconhecer qualquer outro tipo (Yalom, 1998, p.229).

O desenvolvimento e as facilidades da cultura de commodities ${ }^{3}$ têm colaborado para colocar em cena novos valores, novos conceitos de beleza e de cuidados com a saúde. No fim do século XIX e início do XX, a gordura começa a ceder lugar ao corpo violão ou ampulheta, mantendo, no entanto, a generosidade das formas: seios salientes, cintura fina (ainda pelo uso do espartilho, tão difundido no século XIX) e ancas arredondadas, pois a magreza em excesso ainda remetia à idéia de pobreza e/ou de um corpo doente. Segundo Yalom, no século XIX, os espartilhos estavam por todos os lados, não apenas nos corpos de mulheres e raparigas, ou

\footnotetext{
3 Commodity: mercadoria. Que é vendido para a obtenção de lucro. O termo é muitas vezes usado para descrever coisas que podem ser graduadas [medidas] [...] e que são compradas e vendidas numa bolsa de mercadorias, inclusive para entrega futura. Artigo ou objeto de utilidade, mercadoria, bem consumível (Michaelis UOL, acréscimo meu).
}

Movimento, Porto Alegre, v. 9, n. 1, p. 119-143, janeiro/abril de 2003 
nas prateleiras dos armazéns e lojas de roupas íntimas, ou representados em catálogos e revistas. Estavam nas fantasias dos poetas e amantes e na língua dos oradores e reformadores (Yalom, 1998, p. 207).

Os/as oradores/as e reformadores/as, geralmente da área médica, ampliavam suas críticas, em termos de saúde, ao uso do espartilho. Ele foi responsabilizado pela deterioração dos músculos toráxicos, por abortamentos, hemorragias internas e dificuldades para respirar; foi, enfim, a prisão imutável do corpo feminino. As mulheres (feministas da época) que lutavam contra o uso do espartilho falavam de uma nova mulher, formada empreendedora, ambiciosa que foi feita para trabalhar, para ser vista, mas também para gozar a vida; vivendo não apenas para os outros, mas para si, e tanto mais útil quanto mais fiel às suas necessidades (Yalom, 1998, p. 207).

Com o auxílio da transição do espartilho para o soutien, uma importante mudança ocorre na vida das mulheres: pela primeira vez, uma peça de roupa era desenhada exclusivamente para os seios (Yalom, 1998, p. 209) que, diferente do espartilho, não os elevava, mas buscava o conforto. Com isso, o corpo ampulheta foi sendo substituído por corpos cada vez mais magros, obedecendo às exigências de rapidez, agilidade e movimento que a vida moderna e o desenvolvimento industrial demandavam. Os anos 20, segundo Yalom, configuraram-se como uma das irregularidades históricas em que as mulheres buscaram obter uma aparência lisa comprimindo os seios. A indústria da época colaborou, colocando no mercado o soutien em forma de faixa que achatava os seios, inventando uma silhueta masculinizada. A ênfase recaía sobre a simplicidade, liberdade e abandono estilizado (Yalom, 1998 , p. 211), favorecendo a funcionalidade, a praticidade e a agilidade. Em relação a essa necessidade de mudança, funcionalidade, praticidade, rapidez e, necessariamente, adaptação, Bauman indica que,

Num mundo em que coisas deliberadamente instáveis são a matéria-prima das identidades, que sãonecessariamente instáveis, épreciso estar constantemente em alerta; mas acima de tudoé preciso manter a própria flexibilidadee a velocidade de reajuste em relação aos padrões cambiantes do mundo lá fora (Bauman, 2001, p. 100).

A magreza como matéria-prima instável das novas identidades corporais foi-se impondo como norma, e a gordura teve de ser queimada, derretida, apontando a necessidade de adaptarse, ser flexível e acompanhar a precisão de reajuste do corpo.

Movimento, Porto Alegre, v. 9, n. 1, p. 119-143, janeiro/abril de 2003 
Esse novo padrão de corpo, que foi-se configurando e afirmando como verdadeiro ao longo do século passado, intensificou a participação das mulheres na prática de esportes, não só em busca de um corpo em forma e mais saudável, mas também, em busca de novos espaços de convivência e de sociabilidade. Deborah Lupton (2000, p. 33) indica que, desde a virada para o século $\mathrm{XX}$, a participação em atividades esportivas tem sido vista como uma experiência intensa, unindo prazer sensual, autodisciplina, autodescoberta, auto-expressão e plenitude.

A autora conclui a frase citando Mrozeck:

o esporte era um divertimento, assim como uma obrigação - um peculiar mas essencial paradoxo não diferente daqueles que emergem na conversão religiosa (Mrozeck apud Lupton, 2000, p. 33).

Lupton (2000) mostra em uma de suas pesquisas, através de entrevistas realizadas com homens e mulheres diversos, que a saúde é habitualmente reduzida a ser esbelto/a e estar em forma, obedecendo a uma rotina de manutenção do corpo, como não fumar, não beber, praticar esportes com regularidade e não cometer excessos alimentares. As entrevistas foram realizadas por vários pesquisadores/as em diferentes áreas e mostraram resultados semelhantes em relação ao conceito de saúde, entendida como autocontrole, autonegação e força de vontade. Em função disso, normalmente, as pessoas sentem-se culpadas por suas doenças, examinam seus estilos de vida em busca de hábitos não-saudáveis, como não praticar esportes, por exemplo. $\mathrm{O}$ hábito de exercitar-se, principalmente em academias, é o que exige maior persistência, pois caracteriza-se como um trabalho de esforço pessoal,

[...] atua como um marcador da capacidade de um indivíduo para a autoregulação. Esse conceito de exercício está fortemente atrelado ao conceito de saúde como uma criação ou uma realização do eu. Está também relacionado a noçôes contemporâneas mais amplas de corpo ideal como aquele que é controlado firmemente, contido no espaço, destituído de excesso de gordura ou de músculos flácidos (Lupton, 2000, p. 29).

Nessa interessante pesquisa de Lupton, o conceito do que é saúde expresso por diversos indivíduos de uma população qualifica ou exemplifica o conceito de representação que venho utilizando neste texto, pois mostra como um número pequeno de representantes delegam-se o poder de dizer, fazer, decidir, amparados pelo status conferido pela ciência, o que é saúde. As pessoas, grande parte das vezes, repetem os discursos científicos

Movimento, Porto Alegre, v. 9, n. 1, p. 119-143, janeiro/abril de 2003 
como verdades, porque estes estão ancorados num conhecimento considerado legítimo, o da ciência. Esses dizeres tornam-se hegemônicos e representativos das formas de pensar e agir do outro. Quem fala pelo outro controla as formas de dizer do outro (Silva, 1999, p. 34). A mídia, a propaganda, o mercado de consumo, a cultura de commodities, etc., muito têm contribuído para o controle e a produção de identidades sociais e culturais, delegandose o poder de representar e de falar pelo outro. Sinalizo, a seguir, como a medicina social higienista, ao apropriar-se dos discursos eugênicos, buscou, através desses discursos, representar e falar pelo outro. Deste modo, os higienistas constróem, no início do século XX no Brasil, novos conceitos de higiene, de saúde e de corpo em nome da população.

\section{O corpo como lugar da história}

Por volta de 1920/30, foi recolocado em questão e implementado de forma mais efetiva pela medicina social e higienista o discurso da eugenia, que buscava o melhoramento da sociedade através do controle e da conservação da saúde individual e coletiva. Desde seu início, em meados do século XIX, o discurso eugenista tinha como objetivo impedir a reprodução dos que considerava indesejáveis para prevenir a degenerescência, a multiplicação dos inaptos e favorecer a reprodução dos mais aptos (Costa, 1987, p. 19). O movimento eugenista brasileiro apresentava como seu aspecto mais relevante seu foco na saúde pública, no sanitarismo, no higienismo, visando à disciplinarização da população. O movimento apropriou-se do conceito de higiene para implementar o seu discurso, pois preocupava-se com medidas de higiene familiar e sanitária, demonstrando claros objetivos políticos, uma vez que visava, com essas medidas, ao melhoramento e à pureza da raça.

O discurso eugênico, do qual se valiam os médicos higienistas, entendia que mulheres mais saudáveis e ativas teriam filhos geneticamente melhores e superiores, o que tornaria possível uma purificação da raça, caracterizando o caráter eminentemente político desse discurso. Nilson Costa (1987, p. 08) vai dizer que a higiene elaborou a visão apropriada do lugar social da mulher como mulher do lar, mãe dedicada, salvação do homem e instrumento privilegiado de civilização da classe operária e, acresceria, a manutenção da burguesia em ascensão.

Movimento, Porto Alegre, v. 9, n. 1, p. 119-143, janeiro/abril de 2003 
O movimento eugênico, no Brasil, defendia uma abordagem sanitarista com pressupostos baseados na teoria darwinista. Tais teorias, discutidas no campo das ciências humanas e das ciências naturais, investiam na evolução biológica e no aprimoramento da espécie, hostilizando o que era chamado de desvios sociais: homossexuais, delinqüentes, doentes mentais, etc. Esses novos discursos, pretensamente científicos, que se desenvolveram a partir de meados do século XIX, não foram sempre convergentes e/ou monolíticos. A eugenia foi incorporada em diversos campos do saber e instituíram-se muitas correntes eugênicas que divergiam entre si. Os eugenistas cristãos, por exemplo, argumentaram que o darwinismo social era contrário às leis de Deus, era desumano, autoritário, intolerante e pouco educativo. As diferentes vertentes da eugenia traduziram-se em políticas públicas, destinando à mulher grande relevância nesse processo de purificação da raça e de orientação, organização e manutenção do lar, que deveria perfazer uma família nuclear com pai, mãe e, preferencialmente, um casal de filhos.

Confirmando a importância da vigilância higiênica, da medicina e da beleza aliada à saúde, eram os médicos responsáveis pela organização social e moral das famílias de elite que, até início do século XX, tratavam da beleza com produtos ainda considerados remédios: tônicos, loções, pós higiênicos (Sant'anna, 1995). Em função de imposições e pressões sociais, éticas e morais, os cuidados com o corpo não eram tidos como gestos de prazer e de vaidade - características usadas apenas para referir às artistas e às mulheres de "vida fácil" -, sendo chamados de tratamento. As mulheres que se permitissem ou admitissem sentir prazer no cuidado com o próprio corpo deveriam sentir-se culpadas. A ênfase do corpo feminino ainda repousava em sua capacidade de ser mãe:

a alma da beleza está no aparelho reprodutor feminino, insistem os conselheiros e os discursos publicitários (Sant'anna, 1995, p. 124).

Era criticada a mulher que não demonstrasse controle sobre seu corpo: excessos na alimentação, preguiça para as práticas esportivas, desleixo e falta de cuidados consigo mesma. O descontrole e a falta de cuidados das mulheres com seu corpo poderia acarretar fraqueza e doenças, e, de acordo com os discursos médicos que vigoravam, o corpo feminino deveria ser forte e saudável porque útil à sociedade, [ao corpo] são atribuídas diversas privações que objetivam proteger as características da feminilidade e preservar a fertilidade da mulher (Goellner, 2000, p. 87, acréscimo meu).

Movimento, Porto Alegre, v. 9, n. 1, p. 119-143, janeiro/abril de 2003 
Essas eram, ainda, características dos padrões eugênicos que visavam ao fortalecimento da raça através da preparação adequada da mulher-mãe. A autora acrescenta que, em vista disso, o adjetivo reprodutiva aparece, necessariamente, atrelado ao substantivo saúde. Ao tratar das práticas corporais e esportivas em relação ao corpo feminino que foram produzidas no início do século XX, Silvana Goellner diz que

[...] preparar, garantir e conduzir a maternidade com êxito traduzem vontades pessoais e políticas que reclamam precauções e orientações específicas, voltadas para o resguardo e a vigilância do corpo feminino. Para que a mulher possa cumprir essa missão individual e social, é essencial que cultive determinadas normas e condutas que evitem esbanjamentos e violências. É indispensável também que ela aprenda certas formas de ser, de se comportar, de se expressar e de se movimentar com a intenção de salvaguardar aquele queéseu maior atributo: carregar no próprio corpo a esperança de uma outra vida (Goellner, 2000, p. 86).

Ao mesmo tempo em que a preocupação em torno da capacidade reprodutiva da mulher persistia ao longo das décadas, uma outra preocupação invadia o cotidiano feminino. Aquilo que a sociedade da época tomava como feiúra começava a ser visto como um mal que podia ser reparado à custa dos mais variados tratamentos. A partir disso, demarcava-se, em oposição à feiúra, o que era belo - a boa aparência e a boa forma tornavam-se leis. Houve, com isso, um crescimento intenso da indústria da beleza. Os remédios para beleza ganharam uma farmacologia um pouco mais elaborada, e as pomadas prometiam afinar a cintura, branquear a pele, tirar pêlos ou escurecer os cabelos brancos (Sant'Anna, 1995). A maioria dos produtos voltados para os cuidados com a beleza receberam o status de cosméticos. ${ }^{4}$ No final do século XX, as pomadas foram substituídas por géis levíssimos e transparentes que podem ser usados hoje a qualquer hora do dia ou da noite como se fossem uma segunda pele, sem comprometer a aparência e ainda tratar, hidratar, filtrar a luz do sol e prevenir o envelhecimento precoce.

Com o crescimento da indústria de cosméticos e com o surgimento de novas tecnologias para tratar da saúde, da beleza e do bem-estar do corpo, uma série de cuidados foram difundidos e passaram a fazer parte do cotidiano das mulheres. Esses cuidados visavam, entre outras coisas, à manutenção dos laços

4 Refiro-me deste modo à palavra "cosmético" porque, segundo o dicionário, produtos com essa definição são específicos para o embelezamento, para a conservação (creme, preparado, ungüento), e eu acrescentaria para "maquiar" a pele, o corpo, a aparência.

Movimento, Porto Alegre, v. 9, n. 1, p. 119-143, janeiro/abril de 2003 
conjugais, para manter acesa a chama do amor. Apesar do grande avanço da indústria de cosméticos e da nova ênfase dada ao corpo, Sant'Anna (1997) diz que, no começo da década de 1960, presenciava-se uma agudização da obsessão higiênica característica dos discursos eugenistas e moralistas do início do século.

A ênfase demasiada na higiene apontava às mulheres a necessidade de ficarem atentas a todos os cantos e esconderijos da sujeira, não só do corpo, mas também da casa. A autora afirma que os conselheiros da beleza insistiam na necessidade de fiscalizar toda a residência, inclusive o próprio corpo feminino, que era considerado uma extensão da casa. A higiene e o cuidado com as mãos, com unhas limpas e bem cortadas, com os cabelos perfumados e brilhantes e com as pernas depiladas eram sinônimo de saúde, beleza e sedução. Conselhos em torno dessa questão foram localizados em manuais femininos da época, como os exemplos que apresento a seguir, retirados dos livros de Roberto Alencar (1958) e de Helena Sangirardi (1968). Em muitos momentos, suas prescrições eram traduzidas enfaticamente por palavras como limpeza, distinção, arrumação e cuidado, sempre relacionadas ao corpo feminino, numa clara parceria entre beleza, higiene e saúde:

A mulher deve orgulhar-se de sua cabeleira, trazendo-a sempre limpa e discretamente perfumada e sempre arrumada com arte e distinção.

A pele precisa, antes de mais nada, de uma boa limpeza. O uso da água morna e do sabonete podem fazer milagres (Alencar, 1958, p. 47 e 50).

Cheiro de limpeza éo maior imã para um rapaz limpo.

Mas lá um dia, uma alçazinha indiscreta pode resvalar (dos soutiens). Que ela seja, então, imaculadamente tão limpa quanto você [...].

Sem meias, que suas pernas sejam limpas e depiladas ou raspadas (Sangirardi, 1968, p. 26-27).

A indústria de cosméticos, sustentada pelos anúncios publicitários, anunciava a possibilidade de dominar o corpo, de controlar e dissimular seus aspectos físicos através do uso da medicina, de gerenciar seus impulsos de modo que interferissem de forma positiva no seu futuro e no dos seus, melhorando as características raciais. Sangirardi (1968) sugeria à mulher que os cônjuges, antes do casamento, se submetessem a um exame pré-nupcial, determinando o estado de saúde física e mental, assegurando à futura prole vantagens biológicas, morais e sociais e, automaticamente, o melhoramento e o fortalecimento da raça. Essas características da eugenia mostravam uma preocupação pela saúde individual dos sujeitos, a fim de atingir,

Movimento, Porto Alegre, v. 9, n. 1, p. 119-143, janeiro/abril de 2003 
por meio de políticas públicas, a saúde da população de um modo geral para produzir um sujeito social melhorado. Tais discursos, preocupados com a degenerescência da raça, apareciam em livros que serviam, na época, como guia normatizador das condutas femininas. Essa preocupação caracterizava o pensamento dos eugenistas brasileiros, idéias divulgadas e socializadas com maior legitimidade a partir do I Congresso Brasileiro de Eugenia, ocorrido em 1929 (Costa, 1987).

No entanto, com as crescentes críticas aos pressupostos eugênicos, as mulheres começaram a se libertar do domínio médico higienista que proclamava o resguardo, o cuidado e a vigilância do corpo feminino apenas, como apontado por Goellner (2000), para que a mulher pudesse cumprir com sua missão individual e social, a maternidade. Os cuidados com a saúde e a beleza como uma necessidade de prazer, de autoconhecimento e de auto-estima feminina tornaram-se imprescindíveis. Isso possibilitou o fortalecimento, nos anos 60, do discurso psicológico dirigido às mulheres, o qual sugeria o autoconhecimento, a exploração, o toque, o contato íntimo com o próprio corpo com amor e respeito para torná-lo mais autêntico e natural (Sant'Anna, 1995). A abordagem psicológica recrutava e ainda recruta os indivíduos para cuidarem de si mesmos, mas as técnicas usadas pelos especialistas da conduta humana precisam por sua vez moldar a forma como os indivíduos devam pensar sobre si mesmos (Nettleton, 1995, p. 221).

O estudo de diversos autores, segundo Sarah Nettleton, tem apontado que, assim como em outros discursos - da saúde e do cuidado em saúde -, hoje as teorias psicológicas têm contribuído para a reconfiguração do indivíduo usuário de conselhos e de cuidados com a saúde passivo e relativamente dócil para aquele que possui a capacidade de autocontrole, responsabilidade, racionalidade e espírito empreendedor (Nettleton, 1995, p. 213).

Essas teorias produzem e reproduzem identidades, conformando comportamentos e modos de ser, estar, atuar e conviver nos diversos meios sociais em que os sujeitos se desdobram. A identidade não preexiste, não é algo natural, ela é construída por determinados grupos através de sistemas de representação (Silva, 1999). O discurso da teoria psicológica, como qualquer outro discurso, está imbricado em relações de poder. Por meio dessas relações, produz conhecimentos e saberes que determinados grupos buscam definir como verdadeiros, normais e hegemônicos. Deste modo, através do estímulo ao cuidado de si e ao autogoverno, produzem e reforçam novas e outras identidades corporais.

Movimento, Porto Alegre, v. 9, n. 1, p. 119-143, janeiro/abril de 2003 
Com o fortalecimento do discurso da psicologia, foi depositado no amor próprio uma positividade inédita. Entretanto, a busca dessa positividade não se deu sem conflitos, pois a felicidade conjugal - como responsabilidade feminina - continuava a ser uma das principais finalidades dos cuidados com o corpo (Sant'Anna, 1995). A higiene ainda era apresentada como uma característica feminina necessária, que deveria ser colocada em funcionamento como elemento de sedução na conquista de um marido.

Ou seja, enquanto a teoria psicológica buscava apontar, a partir de sua perspectiva, novos horizontes femininos, apresentando novas e outras possibilidades de lidar com a beleza, a saúde, o prazer e o cuidado consigo, o discurso social sobre as mulheres que ainda imperava buscava fixá-la ao lar, ao casamento e aos cuidados com os filhos, tomando essas características como "naturalmente" femininas, como parte de sua identidade. Como aponta Meyer,

Os corpo femininos, as mulheres e em especial as mães, seriam representadas de múltiplas e conflitantes formas, ao longo do século XIX e primeira metade do século XX, em diferentes nações, países e culturas, notadamente em seus momentos de crise: como responsável pela saúde física, emocional emoral do corpo social, como esteio do lar e da família, como agentes de purificação e regeneração racial, como educadoras e símbolos da nação e da pátria e, em contrapartida, como o oposto de tudo isso. (Meyer, 2000, p.124)

Nesse conflito, identidades de gênero eram demarcadas e reforçadas e apontavam as relações desiguais de poder entre homens e mulheres. Essas marcas identitárias tomavam/tomam o corpo como local de inscrição das diferenças e desigualdades de gênero, pois, geralmente, apoiavam-se nas características sexuais biológicas para justificar a produção de tais desigualdades.

Os anos de 1960 e 1970 abriram caminho para algumas rupturas significativas em relação às construções anteriores acerca de representações dominantes de corpo. Metamorfoseando-o como forma de protesto na intenção de liberar o que era entendido como autenticidade e de negar a homogeneização das aparências, de trabalhar o corpo como um refúgio da verdade (Sant'Anna, 2001, p. 21), alguns grupos desse período contestaram a top-modelização e a homogeneização do corpo, que fazia (e ainda faz) a indústria da moda. Esta produz padrões estéticos que atingem a todas/os, dentro e fora do mundo da moda, como, por exemplo, a invenção de modelos esquálidos como Twiggy, que nos anos 60 lançava a magreza como sinônimo de perfeição. Yalom vai dizer que os anos 60 fazem uma retomada dos ideais

Movimento, Porto Alegre, v. 9, n. 1, p. 119-143, janeiro/abril de 2003 
dos anos 20 e que a forma arrapazada popularizada por modelos como Twiggy na Inglaterra e Penelope Tree na América exigia apenas um mínimo de roupa íntima - ou seja, que a mulher fosse magra e de peito liso para começar (Yalom, 1998, p. 216-7).

No entanto, mesmo sem nenhum objetivo ou filiação política, a autora diz que essas modelos foram fortemente associadas às mulheres feministas na popularização do visual assexuado (Yalom, 1998, p. 217). A semelhança entre as mulheres modernas dos anos 60 e as dos anos 20, refere a autora, não se limita à aparência andrógena, mas é marcada também pelo desejo de maior liberdade política e social.

O seu desejo de 'queimar o soutien' tornou-se um grito simbólico para banir todas as formas de opressão interna. Mesmo as mulheres que rejeitavam a palavra 'feminista' viriam, a seu tempo, a gozar os benefícios da libertação feminina (Yalom, 1998, p. 217);

Eu diria que viriam a gozar de alguns aspectos ou de algumas formas de libertação feminina, pois à medida que nos libertamos de alguma forma de subordinação, nos encontramos presas a outras.

No final do século passado, essas representações que tomavam o corpo como um elemento autônomo, independente, capaz de fazer-se mais puro e livre, deixavam de ser vistas como naturais. As configurações de corpo passavam a ser entendidas, principalmente pelo discurso da medicina, da indústria e da mídia, entre outros, como artificiais e efêmeras, porque o corpo podia, a partir de então, ser redefinido e/ou reconstruído. Essa significação do corpo, enquanto projeto, vem subverter as antigas normas para se estabelecer como hegemônica. Essa nova representação passa a apresentar o corpo como um projeto que deveria estar em sintonia com as tecnologias e os objetos de consumo para não se tornar obsoleto. Turbiná-lo, aumentar seus níveis performáticos, adaptá-lo ao uso das novas tecnologias é, desse modo, proporcional ao sonho comum na década de 1960 de retirá-lo da alienação, tornando-o mais verdadeiro e livre ( Sant'Anna, 2000b, p. 21 ) através de um investimento que era/é individual e que exige um esforço contínuo. Yalom fala de uma nova ênfase do corpo, com figuras femininas maiores, mais fortes; diz que, após duas décadas em que a magreza esteve na moda, as mulheres sem seios exibem agora bustos mais proeminentes.

Ofim dos anos 80 foi o apogeu do que a Self [conhecida revista americana] designou as novas Amazonas, com os seus seios surpreendentemente firmes, redondos, perfeitos. Uma psicóloga feminina referiu-se aos implantes mamários como

Movimento, Porto Alegre, v. 9, n. 1, p. 119-143, janeiro/abril de 2003 
um símbolo de status, sugerindo que uma mulher pode comprar um corpo perfeito, do mesmo modo que pode comprar o que quiser. A crença americana na perfectibilidade comercializável tinha chegado ao seio (Yalom, 1998, p. 218).

Para atender as novas demandas de corpo, são colocados em ação os regimes de autocuidado ou de cuidado consigo que, conforme analisa Chris Schilling (1997), ${ }^{5}$ promovem uma imagem de corpo como uma ilha, segura dentro de um sistema global caracterizado por múltiplos riscos. Tais regimes não estão apenas preocupados com a promoção da saúde e a prevenção de doenças, mas estão interessados, também, em fazer com que nos sintamos bem (ter prazer) com nossos corpos e com nossa aparência, oferecendo diversos recursos tecnológicos para que esta seja melhorada, como, por exemplo, através da cirurgia plástica. O cuidado consigo mesma pode ser entendido como uma forma de prazer muito difundida na contemporaneidade. De acordo com Heloisa Bruhns (2000, p. 96), o prazer pode constituir-se na expressão de um querer-viver irreprimível, insistente pelo seu espaço social. Ela acrescenta que o corpo pode tornar-se sinônimo de prazer, que se manifesta numa exaltação ao bem-estar (como se o prazer devesse estar em tudo), contrapondo, dessa maneira, uma aversão ao sofrimento. O prazer torna-se um mandamento naquilo que somos obrigados a fazer (Bruhns, 2000, p. 96-7).

O dever se torna prazer (Bruhns, 2000). Há uma busca desenfreada de transformar o dever em um modo de viver o prazer; o prazer de ser magra, de ser malhada, de ser naturalmente saudável. É como se o rótulo de parecer ter saúde compensasse todos os sacrifícios, convertendo-se em uma agradável sensação de bem-estar. Inverter a citação acima, o prazer torna-se dever, também não pode ser um axioma possível? Pessoas descoladas, de bem com a vida, não são normalmente consideradas como aquelas que sabem tirar proveito da vida, que sabem buscar/sentir prazer?

No entanto, algumas vezes, essas pessoas podem estar sendo controladas pela necessidade e pela obrigação de sentir prazer. O prazer e o dever acabam colocando-se como análogos diante do sujeito, e a ordem de sentir prazer em cumprir seu dever coincide com o dever de sentir prazer (Bruhns, 2000, p. 98). Entendo, a partir das colocações acima, que o prazer, assim como o próprio corpo, é uma construção social. Construímos um mundo de negações, de não deve, mesmo assim, atender essas obrigações, esses deveres, deve caracterizar-se como um prazer: não se deve

5 Traduções livres da autora.

Movimento, Porto Alegre, v. 9, n. 1, p. 119-143, janeiro/abril de 2003 
fumar, não se deve beber, não se deve comer o que quiser, não se deve deixar de praticar exercícios. Assertivas como essas estão presentes em muitas revistas femininas; no entanto, as revistas procuram não utilizar a expressão negativa do não deve, reafirmando, ao contrário, o que é permitido, o que é desejável, e como encontrar prazer neste mundo do sem: sem gordura, sem calorias, sem flacidez, sem barriga, sem excessos, sem doenças, etc.

\section{Por fim...}

A premissa de reconstruir e disciplinar o corpo para atingir a boa forma, nos moldes em que esta passa a ser definida e vivida ao longo do século XX, passa a ser um modo de viver a vida que deve ser incorporado ao cotidiano de cada um/a, bem como uma alternativa de prazer, um modo de aliviar o estresse, uma forma de divertimento e distração que conta com o uso de recursos tecnológicos e científicos: cosméticos, cirurgias plásticas, dietas, academias, massagens, atividades físicas. Nesse contexto, ser belo é aproximar-se de um ideal sempre determinado de modo universal, distinto do que é cada corpo, enquanto este, por sua vez, é considerado um ente particular elocal (Sant'Anna, 2001, p. 108). O corpo, nas últimas décadas do século XX, foi pensado como um território inexplorado e natural:

O corpo humano, derradeiro território a ser conquistado, desvendado e controlado, revela-se assim um campo preferido às experimentaçốes da biotecnologia e dos investimentos da economia de mercado, justamente quando é fortalecido um paradoxo das sociedades industriais: por um lado, tem-se o culto, a adoração, a valorização extrema das aparências e da saúde; por outro, a fragmentação do organismo e das terapias em expansão, a dispersão de células, genes e órgãos, além do comércio desses materiais em larga escala (Sant’Anna, 2001, p.76).

O corpo passa a ser manipulado e comercializado de forma intensa. Como diz Donna Haraway (2000), o corpo que temos hoje é um híbrido de natureza e tecnologia. O híbrido, segundo Silva (2000, p. 87), pode estar ligado aos movimentos demográficos que permitem o contato entre diferentes identidades: as diásporas, os deslocamentos nômades, as viagens, os cruzamentos de fronteiras. O autor segue dizendo que esses cruzamentos, na perspectiva da teoria cultural contemporânea, podem ser literais ou simplesmente metáforas. Para ele, cruzar fronteiras pode significar simplesmente mover-se livremente entre os territórios simbólicos de diferentes identidades. 'Cruzar fronteiras' significa não respeitar os sinais que demarcam - 'artificialmente' - os limites entre os territórios das diferentes identidades (Silva, 2000, p. 88).

Movimento, Porto Alegre, v. 9, n. 1, p. 119-143, janeiro/abril de 2003 
Entendo, com isso, que vivemos um deslizamento, um cruzamento de fronteiras entre o corpo e as tecnologias, colocando em cheque conceitos como saúde e beleza ou oposições como humano e máquina, ${ }^{6}$ pois não há um limite que possa ser estabelecido para determinar o que é saúde e o que é beleza, onde termina o corpo e onde começa a máquina. $\mathrm{O}$ fato de estar na fronteira ou de cruzá-la e recruzá-la é uma demonstração do caráter artificialmente imposto das identidades fixas (Silva, 2000, p. 89).

Os processos de significação pelos quais o corpo tem sido narrado e que procurei evidenciar neste texto permitem percebêlo como lugar da história. Permitem entender porque o corpo é um construto social e cultural fabricado no cotidiano. Isso quer dizer que o corpo não tem em si mesmo nenhum significado intrínseco, ele é um conjunto de signos, produto de representações que, por meio de múltiplas estratégias, buscam "fixar" uma identidade sobre ele.

\section{Health and beauty of the female body - some representations in Brazil in the twentieth century}

Abstract: There is a set of knowledges and devices that tell us what the body is. These multiple devices, such as the media, the avertising and the industry, for instance, produce several representations of body. In the theoretical field of Cultural and Gender Studies, to which this text belongs, representation is understood as a way of producing meanings in the culture scope. These meanings are produced through language and are implied in power relationships. Positions of subjects, differences and identities are built through these relationships. In this text, I have tried to situate the body, mainly the female one, as a historical, social and cultural construction, produced in multiple ways in time and space. I have localized some of the transformations, permanences and/or disruptions operated in representations of the female body in the interrelation between health and beauty throughout the twentieth century. I have pointed out, to a certain extent, how the hygienistic social medicine took hold of eugenic discourses, aiming at producing new concepts of hygiene, health and body for the population. I have

6 Para um aprofundamento da discussão sobre o "borramento" das fronteiras entre humano e máquina na área da saúde, ver a dissertação de Mara Ambrosina de 0 . Vargas: Corpus ex machina: a ciborguização da enfermeira no contexto da terapia intensiva, 2002.

Movimento, Porto Alegre, v. 9, n. 1, p. 119-143, janeiro/abril de 2003 
continuação...

concluded that reconstructing and disciplinating the body to reach fitness, in the way it was defined in the twentieth century, become a life style that must be incorporated into the individual's quotidian, as well as an alternative of pleasure and health that counts on the use of different technological and scientific resources.

Keywords: body, health, beauty.

\section{Salud e belleza del cuerpo femenino - algunas epresentaciones en el Brasil del siglo $x x$}

Resumen: Hay un conjunto de conocimientos y de instancias que nos dicen lo que es el cuerpo, estas múltiples instancias como la midia, la publicidad, y la industria, por ejemplo, producen diversas representaciones del cuerpo. Dentro del campo teórico de los Estudios Culturales y de Género, en el que este texto se inserta, representación es entendida como un modo de reproducir significados en el ámbito de la cultura. Estos significados son producidos a través del lenguage y estan inplicados en relaciones de poder. Por medio de estas relaciones, posiciones de sujeto, diferencias e identidades son construídas. En este texto procuro situar el cuerpo, príncipalmente el femenino, como un construto histórico, social y cultural, producido de multiples formas en el tiempo y en el espacio. Localizo algunas de las transformaciones, y permanencias $y / 0$ rupturas operadas en las representaciones del cuerpo femenino en la interacción entre la salud y la belleza en el decorrer del siglo XX. Señalizo en alguna medida, como la medicina social higienista se apropió de los discursos eugénicos con la intención de producir nuevos conceptos de higiene, de salud y del cuerpo en nombre de la población.Concluyo que reconstruir y disciplinar el cuerpo para alcanzar la "buena forma", en los moldes como fueron definidos en el decorrer del siglo XX, pasa a ser un modo de vivir la vida que debe ser incorporado al cotidiano de cada un/a, bien como una alternativa de placer y salud que cuenta con el uso de los más diversos recursos tecnológicos y científicos.

Palabras clave: cuerpo, salud e belleza. 


\section{Referências}

ALENCAR, Roberto. Como vencer no amor. São Paulo: Prelúdio, 1958. Edição para mulher.

BAUMAN, Zygmunt. Modernidade Líquida. Rio de Janeiro: Jorge Zahar, 2001.

BRUHNS, Heloisa Turini. O corpo contemporâneo. In: .; Gutierrez, Gustavo Luis (Org.). O corpo e o lúdico: ciclo de debates lazer e motricidade. Campinas: Autores Associados, 2000, p. 89-102.

COSTA, Nilson do Rosário. Estado, educação e saúde: a higiene da vida cotidiana. Cadernos Cedes, Campinas, n. 4, p. 5-27, 1987.

GASTALDO, Denise. É a educação em saúde saudável?: repensando a educação em saúde através do conceito de bio-poder. Educação e Realidade, Porto Alegre, v. 22, n. 1, p. 147-168, jul./dez. 1997.

GOELLNER, Silvana Vilodre. Mulheres em movimento: imagens femininas na Revista Educação Physica. Educação e Realidade, Porto Alegre, v. 25, n. 2, p. 77-94, jul./dez. 2000.

HARAWAY, Donna. Manifesto ciborgue: ciência, tecnologia e feminismo-socialista no final do século XX. In: SILVA, Tomaz Tadeu (Org.). Antropologia do ciborgue: as vertigens do pós-humano. Belo Horizonte: Autêntica, 2000, p. 37-129.

LUPTON, Deborah. Corpos, prazeres e práticas do eu. Educação e Realidade, Porto Alegre, v. 25, n. 2, p. 15-48, jul./dez. 2000

MEYER, Dagmar E. Estermann. Identidades traduzidas: cultura e docência teuto-brasileiro-evangélica no Rio Grande do Sul. Santa Cruz do Sul: Ed. Sinodal, EDUNISC, 2000

MEYER, Dagmar E. Estermann. As mamas como constituinte da maternidade: uma história do passado? Educação e Realidade, Porto Alegre, v. 25, n. 2, p.117133, jul./dez. 2000.

MIRA, Maria Celeste. O leitor e a banca de revistas: a segmentação da cultura no século XX. São Paulo: Olho D'água/ Fapesp, 2001.

NETTLETON, Sarah. Governing the risky self: How to become healthy, wealthy and wise. In: Petersen, A. Buton, B. Foucault health and medicine. London/ New York: Routledge, 1997, p. 207-222.

SANGIRARDI, Helena. Vida em sociedade e no lar. São Paulo: Nacional de Livros, 1968. (Coleção feminina, vol. 4.)

SANGIRARDI, Helena. Corpo e história. In: Seminário sobre a contemporaneidade, 2., 2000, Feira de Santana. O corpo ainda é pouco. Feira da Santana: NUC/UEFGS, 2000b, p. 79-88.

SANGIRARDI, Helena . Corpos de passagem: ensaios sobre a subjetividade contemporânea. São Paulo: Estação Liberdade, 2001.

SANGIRARDI, Helena. Cuidados de si e embelezamento feminino: fragmentos para uma história do corpo no Brasil. In: (Org.). Políticas do corpo:

Movimento, Porto Alegre, v. 9, n. 1, p. 119-143, janeiro/abril de 2003 
elementos para uma história das práticas corporais. São Paulo: Estação Liberdade, 1995, p.121-139.

SANGIRARDI, Helena. Descobrir o corpo: uma história sem fim. Educação e Realidade, Porto Alegre: v. 25, n. 2, p. 49-58, jul./dez. 2000a.

SANGIRARDI, Helena. O corpo entre antigas referências e novos desafios. Cadernos de subjetividade, São Paulo, v. 5, n. 2, p. 275-284, dez. 1997.

SCHILLING, Chris. The body and difference. In: WOODWARD, Kathryn. Identity and difference. London: Sage/Open University, 1997.

SILVA, Tomaz Tadeu. A produção social da identidade e da diferença. In: (Org.). Identidade e diferença: a perspectiva dos estudos culturais. Petrópolis: Vozes, 2000, p. 73-102.

SILVA, Tomaz Tadeu . O Currículo como fetiche: a poética e a política do texto curricular. Belo Horizonte: Autêntica, 1999.

VEIGA-NETO, Alfredo. As idades do corpo: (material)idades, (divers)idades, (corporal)idades, (ident)idades... In: Garcia, Regina Leite. (Org.). O corpo que fala dentro e fora da escola. Rio de Janeiro: DP\&A, 2002, p. 35-64.

YALOM, Marilyn. História do seio. Lisboa: Teorema, 1998. 